\title{
Aspects Regarding the Use of Topographic Measurements for Monitoring Drăgan Valley Dam
}

\author{
Paul SESTRAŞ ${ }^{1,2}$, Tudor SĂLĂGEAN ${ }^{2 *}$, Marcel DÎRJA², Mircea ORTELECAN², \\ Dan VELE ${ }^{3}$, Diana FICIOR ${ }^{2}$, Jutka DEAK ${ }^{2}$ \\ ${ }^{1}$ University of Agronomic Sciences and Veterinary Medicine Bucharest, 59 Mărăşti Blvd, District 1, \\ 011464, Bucharest, Romania, Phone: +4021.318.25.64, Fax: + 4021.318.25.67 \\ ${ }^{2}$ University of Agricultural Sciences and Veterinary Medicine Cluj-Napoca, Calea Mănăştur 3-5, 400372, \\ Cluj-Napoca, Romania, Phone: +40264.596.384, Fax: +40264.593.792 \\ ${ }^{3}$ Babeş Bolyai University, Faculty of Geography, Clinicilor Str. 5-7, 400006, Cluj-Napoca, Romania, \\ Phone: +40264. 592.214 \\ *)Corresponding author, e-mail: tudor.salagean@usamvcluj.ro
}

BulletinUASVM Horticulture 72(2) / 2015

Print ISSN 1843-5254, Electronic ISSN 1843-5394

DOI:10.15835/buasvmcn-hort: 11578

\begin{abstract}
Dragan Valley Dam is located in Cluj County near Ciucea and is built on plots and blades in double arc. With a height of $120 \mathrm{~m}$ and a canopy length of $424 \mathrm{~m}$, the dam is considered the fifth largest in the country. The paper aims to present the horizontal displacements of the tracking landmarks embedded in the downstream face of the dam and the vertical displacements of the landmarks located on the crest of the dam. In order to determine the horizontal displacements was created a micro-triangulation network in a local coordinate system, which has the X axis oriented on the direction downstream-upstream of the dam, and the $Y$ axis with the direction on the left bank of the dam. The support network is formed of eleven pillars placed on the dam bedrock and sixty-nine tracking marks placed on the downstream of the dam. The altimetric network is formed of thirty-three leveling landmarks located on the dam crest and two fixed landmarks situated at the edges of the dam. The planimetric measurements were made with a Leica TS30 total station, and the altimetric measurements with Leica DNA 03, which provides an accuracy of $0.3 \mathrm{~mm} / 1 \mathrm{~km}$ of double leveling. After processing the azimuthal measurements using the indirect measurements method and the statistical assumptions, the pilasters I, II and VII were considered as fixed stations. The maximum displacements were recorded at landmark R7 $(-42.3 \mathrm{~mm})$ and the maximum compaction was recorded at the landmark R33. The horizontal and vertical displacement values of the planimetric and altimetric landmarks, which were obtained after carrying out the topographical observations and their processing, falls within the allowable tolerances, which shows stability in the functionality of the dam.
\end{abstract}

Keywords: basis epoch, current epoch, dam crest, parament, tracking marks.

\section{INTRODUCTION}

Drăganului Valley Dam (Floroiu) (Fig.2-4) is located in Cluj county, Romania, at the confluence with the creek Drăgan and the creek Sebeșel (Fig. 1), near Ciucea village. The dam is built on 33 plots of $12 \mathrm{~m}$ length, double arch, with the following geometrical parameters:

The dam was put in charge in 1984 and the normal level of retention elevation was reached in 1995. From the point of view of its geometric parameters is considered the fifth largest dam in Romania.

The tracking geodetic network of Drăgan dam consists of two distinct components, one for tracking the horizontal displacements, and the second to determine the vertical displacements.

The geodetic network for planimetric tracking of Drăgan dam (Fig. 5) is a microtriangulation network of eleven pillars; the background is on the 
base rocks and 69 tracking marks mounted on the downstream parament of the dam (Fig. 6).

The altimetric network (Fig. 7) is formed of 33 leveling landmarks located on the crest of the dam and two fixed points located at the ends of the dam, materialized by landmarks. The status of the leveling landmarks apparently is good but in reality the landmark RND, on the right bank, was tapped by $33.2 \mathrm{~mm}$.

When designing the tracking stations, related to the monitored objectives, must be taken into account to ensure the accuracy required in determining the displacements of the sighting marks and ensuring the stability of the tracking stations throughout the entire period in which the

Tab.1. Geometrical parameters of the dam

\begin{tabular}{cc}
\hline - dam height - $120 \mathrm{~m} ;$ & \\
- length at the crest $-424 \mathrm{~m} ;$ & - elevation of the minimum level \\
- thickness at the crest - $6 \mathrm{~m}$ & of exploitation - $792 \mathrm{~m}$ \\
- thickness at the basis - $28 \mathrm{~m}$ & - crest elevation $-856 \mathrm{~m}$ \\
- elevation of the normal level & - foundation elevation - $736 \mathrm{~m}$ \\
of retention (NNR) - $851 \mathrm{~m}$ & \\
\hline
\end{tabular}

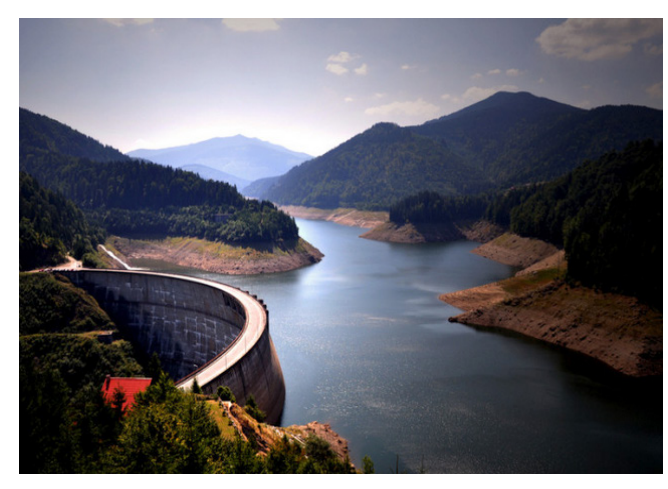

Fig. 2. Dam view (N-S) and the accumulation lake source: http://www.roturism-info.ro/

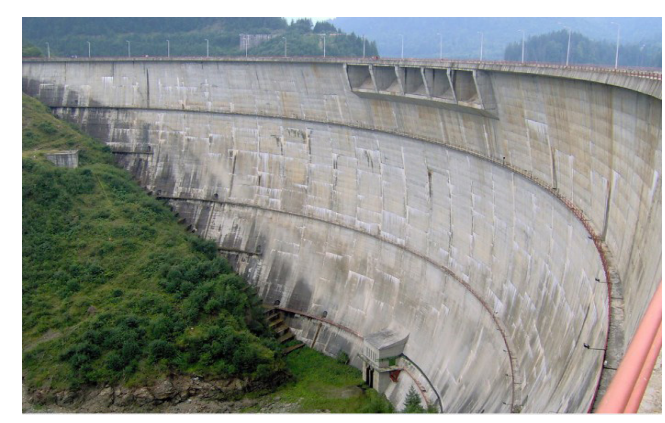

Fig. 3. Dam view (N-S) source: personal photo measurements are made (Kalkan et al., 2010; Li and Wang, 2011; Ortelecan and Pop, 2005).

\section{MATERIALS AND METHODS}

For determining the horizontal displacements was achieved microtriangulatio network (Fig. 5) in a local coordinate system with the $\mathrm{X}$ axis direction oriented downstream-upstream of the dam and the $\mathrm{Y}$ axis with a direction of growth to the left bank. The support network is formed of eleven pillars funded on bedrock and 69 tracking marks mounted on the downstream face of the dam. The altimetric network (Fig. 7) is formed of 33 leveling landmarks placed on the dam crest and two fixed points located at the ends of the dam, materialized by landmarks.

The planimetric measurements were performed with the total station Leica TS30, and the altimetric measurements with the level Leica DNA 03.

In the current tranche of measurements (October 2014), the pillars are presented in good use, but due to vegetation growth the visibility among a number of pillars has been discontinued.

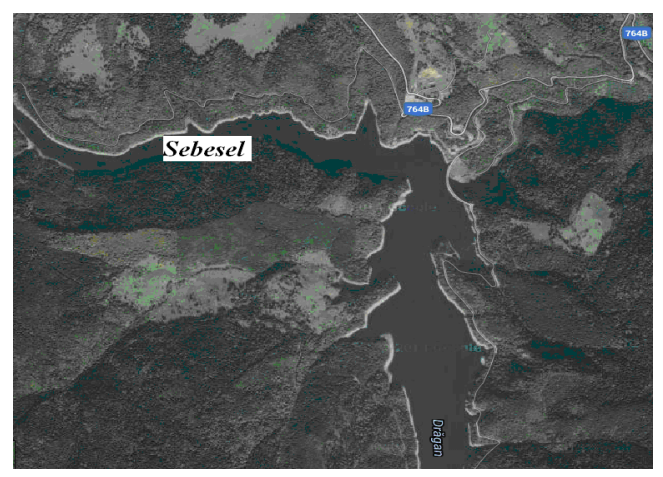

Fig. 1. Dam positioning source: https://www.google.ro/maps

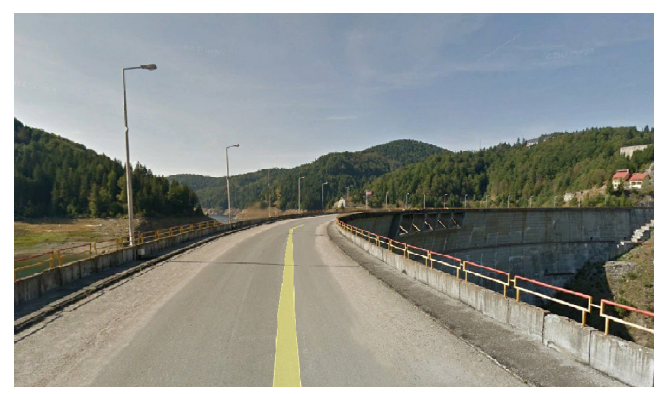

Fig. 4. Dam view at the crest, $(\mathrm{S}-\mathrm{N})$ source: personal photo 
The tracking marks on the downstream face of the dam is presented in good condition except the marks 44, 59 and 63 which were covered with mortar or limestone deposits and the mark

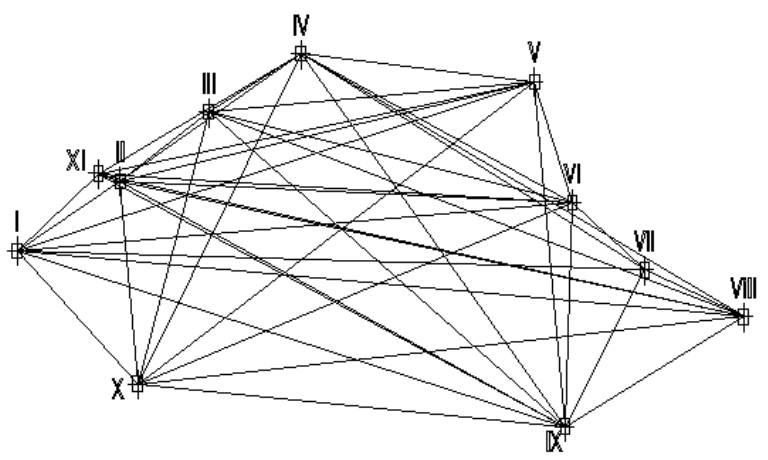

Fig. 5. Sketch of the tracking network
68 which was destroyed. Due to obstacles arising between pillars and the sight marks, the network configuration in the current epoch will be different from the base epoch.

The measurements performed in the planimetric network were compensated, in a first step, as measurements in a free network. This was done in order to determine the fix points.

Following the rigorous compensation of the level differences measured in the leveling network which is supported at the endings on fix points, was obtained an accuracy for determining the leveling traverse the heads fixed, obtained accurate determination of point compaction of $0.59 \mathrm{~mm}$.

In order to monitor the dam taken into study, there have been several topographic measurements, which will be correlated with

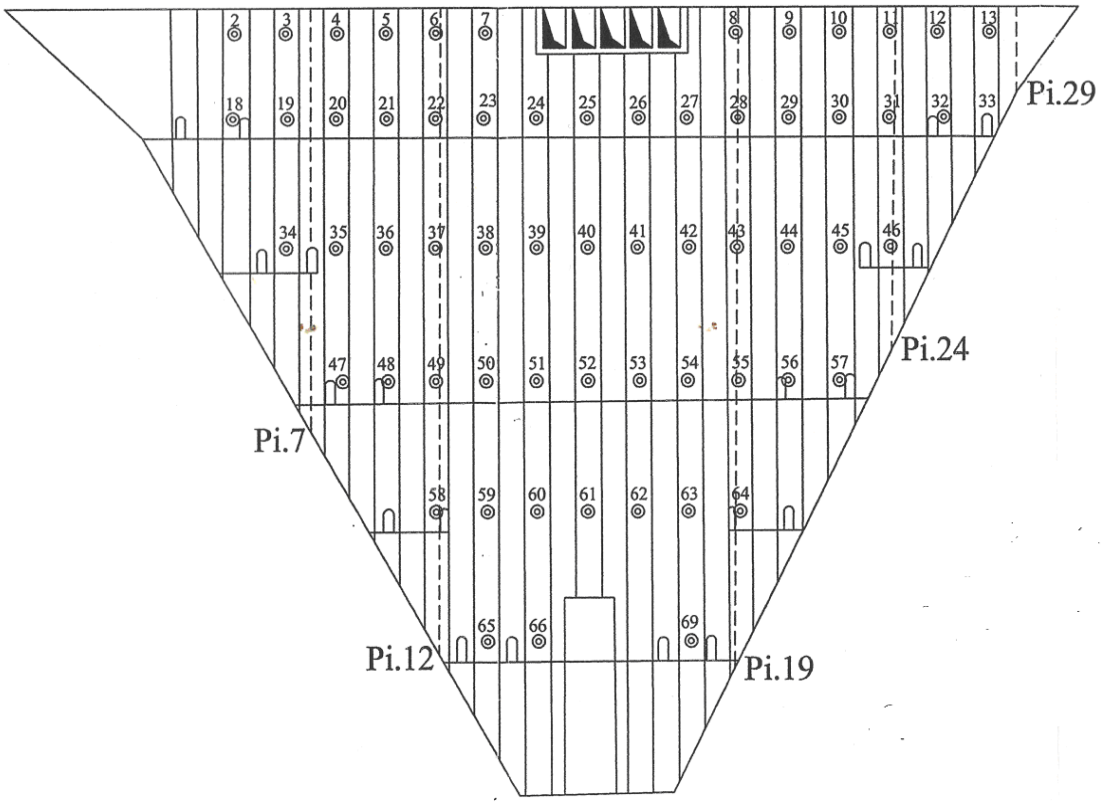

Fig. 6. Sketch of the location of the tracking marks on the downstream parament

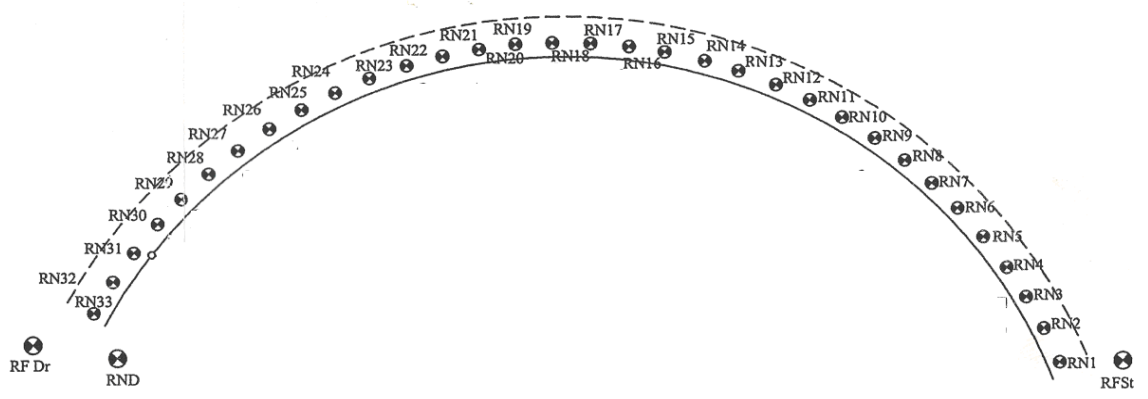

Fig. 7. Sketch with the location of the leveling landmark on the dam 
physical measurements obtained at direct and indirect pendulums (Ortelecan et al., 2010).

In the processing of topographic observations, planimetric and altimetric, it is used in general the indirect measurement method (Ghițău, 1983; Ortelecan, 2006), in which the linearized system of equations of corrections has the following form:

$$
A X+l=V, \quad P
$$

where:

A - coefficient matrix;

$\mathrm{X}$ - the unknown elements of the system;

$\mathrm{l}$ - the free terms;

$\mathrm{V}$ - the correction of the measured elements;

$\mathrm{P}$ - measurement weight.

The most probable values of the unknown parameters, obtained in the minimum condition are calculated with the following relation:

$X=-N^{-1} A^{T} P l$

where:

$N=A^{T} P A$

The standard deviation of the wheight unit is calculated with the relation:

$s_{0}=\sqrt{\frac{v^{T} P v}{n-u}}$

where:

$\mathrm{n}$ - number of the equations;

$\mathrm{u}$ - number of unknown elements;

If the unknown paramteres ar subject to some conditions like the following:

$B X+W=0$

where:

$\mathrm{B}$ - the matrix of unknown coefficients imiplicated in conditions;

$\mathrm{W}$ - the vector of free terms.

The Lagrange function of conditioned minimum (Dima et al., 1999) is given by the relation:

$$
\left.V^{T} P V-2 k^{T}(B X+W) \rightarrow \operatorname{minim}\right)
$$

In this case the solutions of the corrections equation system, corresponding to indirect measurements which are subject to conditions is determined by the following relation:
$X=N^{-1} B^{T} k-N^{-1} A^{T} P l$

where:

$k=\left(B N^{-1} B^{T}\right)^{-1} B N^{-1} A^{T} P l-\left(B N^{-1} B^{T}\right)^{-1} W$

In the case of indirect measurements, if the number of measurements made in the network is greater than the number unknown parameters ( $n>\mathrm{u}$ ) (Moldoveanu, 2002) and as such the matrix of coefficients of the linear equations system " $\mathrm{A}$ " has a surjective defect which is eliminated by the minimum condition ( $\mathrm{V}^{\mathrm{T}} \mathrm{PV} \rightarrow$ minimum).

In the case of indirect measurements subjected to conditions, if the matrix " $B$ " has the rank " $r$ " which is less than the number of unknown parameters " $\mathrm{u}$ " $(\mathrm{r}<\mathrm{u})$, with relation (5) is removed from relation (1) the " $r$ " unknown parameters . If the rank of matrix " $B$ " equals the number of unknown parameters $(r=u)$ then the unknown parameters are uniquely determined and calculated with:

$X=-B^{-1} W$

In the case of free geodetic networks, if the rank of the matrix " $\mathrm{A}$ " and " $\mathrm{N}$ " noted with " $\mathrm{r}$ " is smaller than the number of unknown parameters " $u$ " ( $r$ $<u$ ), then the matrix are unique and have a rank defect injection $(\mathrm{d}=\mathrm{u}-\mathrm{r})$. In this situation solving the support networks is accomplished through Mittermayer method and Hansen-Helmert-Wolf algorithm (Niemeier, 1980).

From processing separated on measurement epochs will result the coordinates $\mathrm{X}_{\mathrm{i}}$, in the current phase, the measurement corrections " $\mathrm{V}_{i}$ " and the precision indices " $\mathrm{S}_{0}$ ", " $\mathrm{S}_{\mathrm{x}_{i}}$ ", the average standard deviation on the network. The displacements along the axes X, Y are obtained as a difference between the coordinates in the two measurement epochs at time $\mathrm{T}_{0}$ and $\mathrm{T}_{\mathrm{i}}$ :

$d_{i}=X_{i}-X_{0}$

where:

$\mathrm{X}_{0}$ - coordinates at the basis measurement;

$\mathrm{Xi}$ - coordinates at the current measurement.

In the case of altimetric measurements, the compaction of the leveling marks are obtained with the relation:

$T_{i}=H_{i}-H_{0}$

where:

$\mathrm{H}_{0}$ - the altimetry at the basis measurement;

$\mathrm{Hi}$ - the altimetry at the current measurement. 
The functional model for processing " $\mathrm{k}$ " measurement epoch ( $k>1$ ) is given by the following relation:

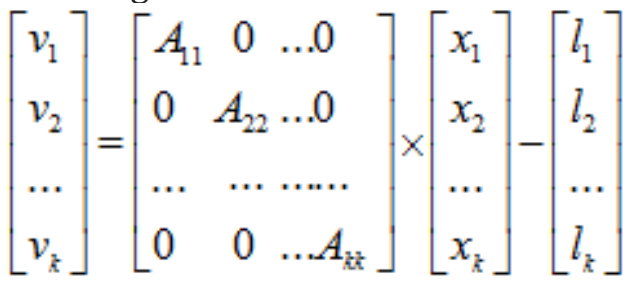

Each position within the functional model will result from processing and compensation of the measured values at different measurement epochs.

It is considered that the submatrices $A_{i j}=0$ for $i \neq j$, due to the low possiblities for evaluating the links between measurement epochs.

The stochastic model contains in addition to the systematic errors, random errors which constitute random variables.

The $Q_{i j}$ submatrices, where $i \neq j$, expressed from the stochastic point of view, the link between the measurements made at different measuring epochs, link which extremely difficult to predict and generally is considered equal to zero.

The simplified stochastic model will be defined by the equation:

$$
C_{m m}=\sigma_{0}^{2} Q_{m m}=\sigma_{0}^{2}\left[\begin{array}{cccc}
Q_{11} & 0 & \ldots & 0 \\
0 & Q_{22} & \ldots & 0 \\
\ldots & \ldots & \ldots . . \\
0 & 0 & \ldots & Q_{k k}
\end{array}\right]
$$

The compensation of the measured values in the tracking geodetic network at a certain measurement epoch it is made according to the compensation free geodetic networks:

- for each measurement epoch are kept the same provisional coordinates for the points of the tracking geodetic network;

- the configuration of the tracking geodetic network, at different epochs, may be the same or variable over time by changing the number of points on the network, as well as changes in the measurements plan;

- the statistical analysis of the significance of the displacements is based on the information provided by the compensations at each measuring epoch;
- if after the test are determined significant displacements of the points, the next step consists on locating these points.

\section{RESULTS}

After processing azimuthal measurements using the indirect measurements method and the statistical assumptions were considered as fixed stations the pillars I, II and VII. The maximum displacements to downstream were recorded at mark R7 (-42.3 $\mathrm{mm}$ ) and maximum compaction was registered at mark R33.

To compensate the measurements made in the microtriangulation network, through stability testing were determined as fix the pillars I, II and VII.

The values of the displacements obtained from the tracking marks located on the downstream in June and October 2014 are shown in Fig.8a-8j and the vertical displacements registered at the leveling marks situated on the crest of the dam are shown in Fig.9.

The displacements from upstream - downstream of the marks fluctuates in admisible limits depending on the water level in the dam at the time of topographical observations. Higher amplitudes of displacements are recorded in the central area of the dam above the average level.

In the graphs above (fig. 8a-j), which present the horizontal displacements of the landmarks, it can observed a deviation from the profile curves of the landmark 44 (in October), respectively for the landmarks 51 and 54 (in June).

The deviations are due to the accuracy of determining the coordinates of the points, whose causes are found in the difficulties of sight due to the obstacles emerged from the vegetation growth.

\section{CONCLUSIONS}

The horizontal and vertical displacement values of the planimetric and altimetric landmarks, which were obtained after carrying out the topographical observations and their processing, falls within the allowable tolerances, which shows stability in the functionality of the dam. The displacements analysis shows a high degree of complexity and a high volume of calculations that will be made after the processing epoch for each measurement separately. It is necessary to use specific methods of mathematical statistics, because in this way it examines the significance 


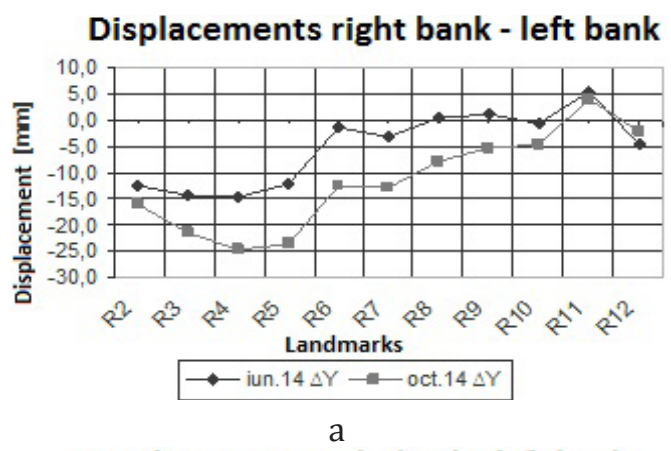

Displacements right bank - left bank
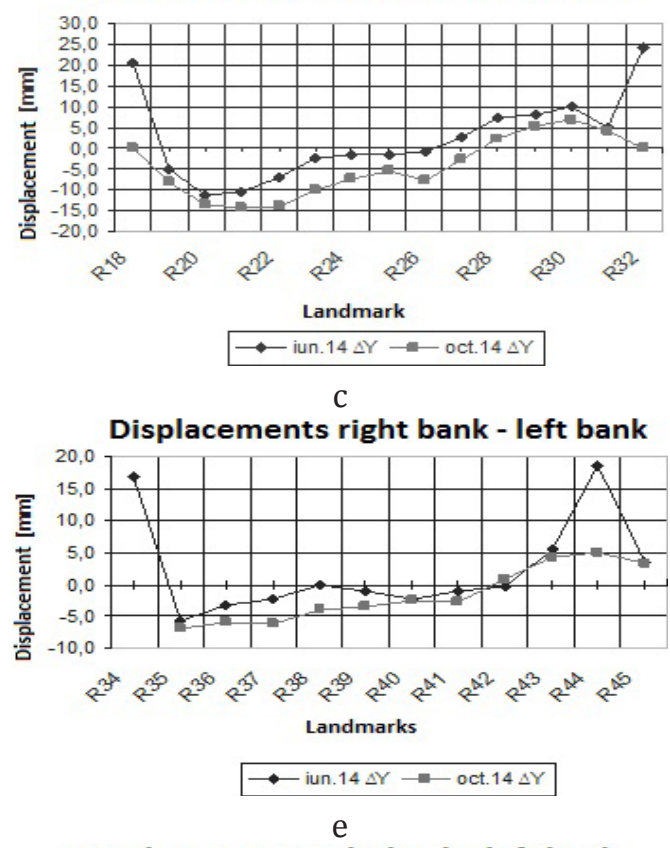

\section{Displacements right bank - left bank}

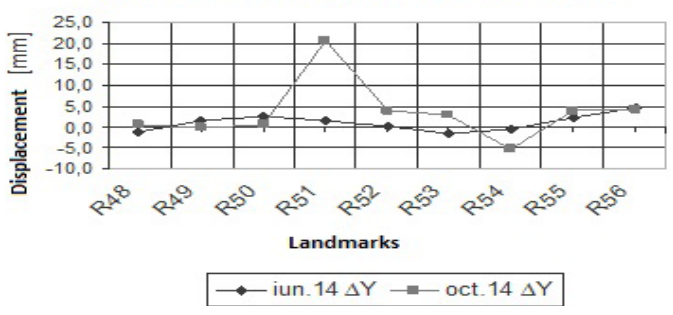

Displacements right bank - left bank

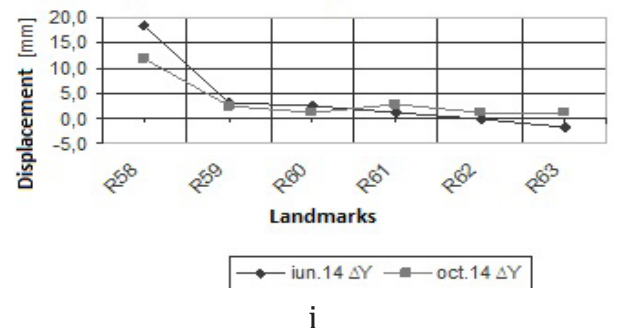

\section{Displacements upstream-downstream}

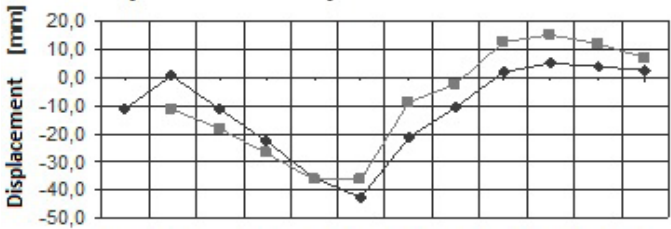

से से से से से से से से से से

Landmarks

$\longrightarrow$ - iun.14 $\Delta \mathrm{X} \rightarrow-$ oct.14 $\Delta \mathrm{x}$

$b$

Displacements upstream - downstream

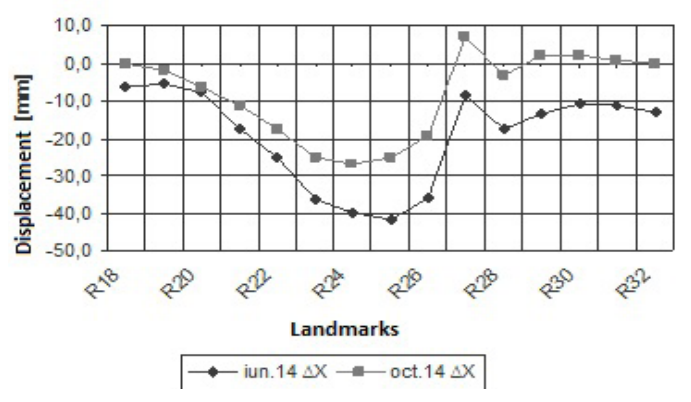

d

Displacements upstream - downstream

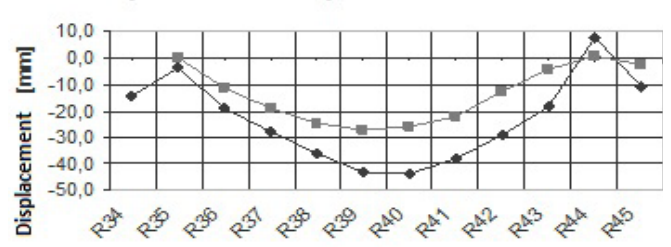

Landmarks

$$
\longrightarrow-\text { iun.14 } \Delta X \rightarrow \text { oct.14 } \Delta X
$$

$f$

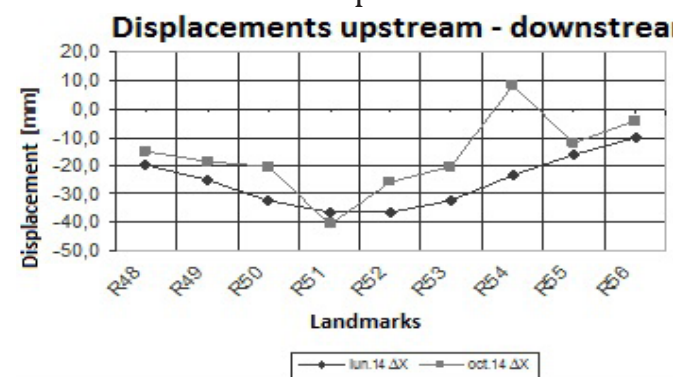

$\mathrm{h}$

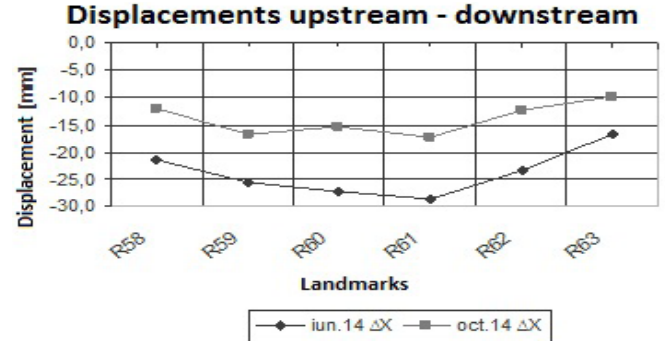

j

Fig. 8. Horizontal displacements obtained in June and October 2014 


\section{Vertical displacements}

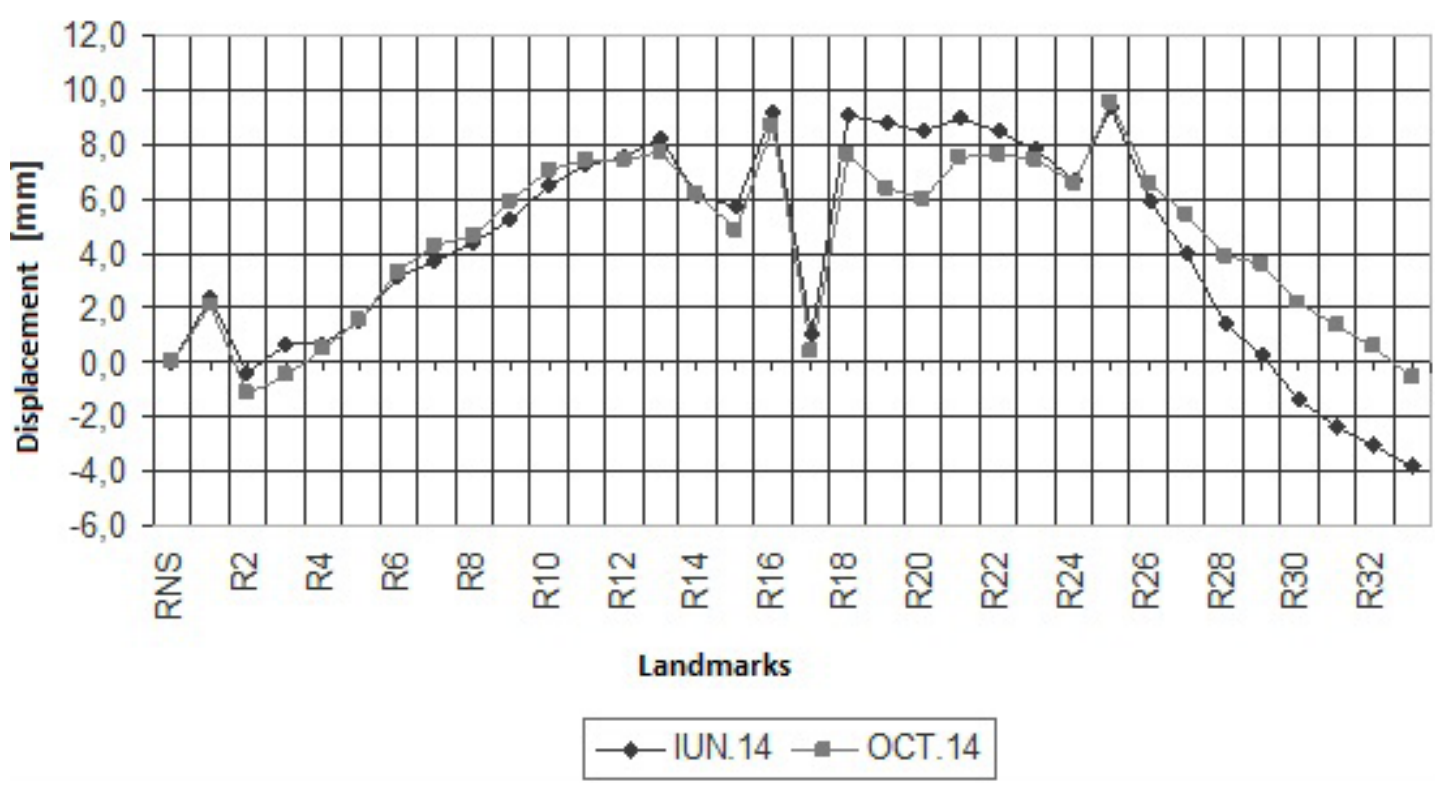

Fig. 9. Vertical displacements

of displacements from the statistically point of view, respectively it determines if the differences between the are due to measurement errors or to actual displacements suffered by points. From the graphic representations of the horizontal and vertical displacements we can identify the points that have been determined wrong in different measurement epoch or at the basis measurement.

\section{REFERENCES}

1. Dima N., Herbei O., Vereș I. (1999). The theory of errors and least squares method. Universitas Publishing House, Petroșani, Romania.

2. Ghițău D. (1983). Geodesy and geodesic gravimetry Didactic and Pedagogic Publishing House, Bucharest, Romania.

3. Kalkan Y., Alkan R., Bilgi S. (2010). Deformation Monitoring Studies at Ataturk Dam. Proceedings of the XXIV FIG Congress "Facing the Challenges - Building the
Capacity", 11-16 April 2010, Sydney, Australia, ISBN 97887-90907-87-7: 10-24.

4. Li W.,Wang C. (2011). GPS in the Tailings Dam Deformation Monitoring. Procedia Engineering, 26: 1648-1657.

5. Moldoveanu C. (2002). Geodesy. Matrix Rom Publishing House, Bucharest, Romania.

6. Niemeier W. (1980). Ausgleichung geodatischer Netze. GNLI Publishing House, Stuttgart, Germany.

7. Ortelecan M., Pop N. (2005) Topographical methods of tracking the behaviour of constructions and surrounding lands. AcademicPres Publishing House, Cluj-Napoca, Romania.

8. Ortelecan M. (2006). Geodesy. AcademicPres Publishing House, Cluj-Napoca, Romania.

9. Ortelecan M., Ana Ciotlăuș, Sălăgean T., Diana Ficior, Pop N., Lupuț I., Vele D. (2012). Considerations Regarding Hydro Power Station Monitoring Objectives Through Geodetic Measurements, Bulletin UASVM Horticulture 69(2): 477-485. 